\title{
Recent Developments in Vascular Adventitial Pathobiology
}

\section{The Dynamic Adventitia as a Complex Regulator of Vascular Disease}

\author{
Maria G. Tinajero and Avrum I. Gotlieb
}

From the Faculty of Medicine, University of Toronto, Toronto, Ontario, Canada

\author{
Accepted for publication \\ October 29, 2019 \\ Address correspondence to \\ Avrum I. Gotlieb, B.Sc., \\ M.D.C.M., University of \\ Toronto, Medical Sciences \\ Bldg., Room 6275A, 1 King's \\ College Circle, Toronto M5S \\ $1 \mathrm{~A} 8$, ON, Canada. E-mail: \\ avrum.gotlieb@utoronto.ca.
}

\begin{abstract}
The adventitia, the outer layer of the blood vessel wall, may be the most complex layer of the wall and may be the master regulator of wall physiology and pathobiology. This review proposes a major shift in thinking to apply a functional lens to the adventitia rather than only a structural lens. Human and experimental in vivo and in vitro studies show that the adventitia is a dynamic microenvironment in which adventitial and perivascular adipose tissue cells initiate and regulate important vascular functions in disease, especially intimal hyperplasia and atherosclerosis. Although well away from the bloodwall interface, where much pathology has been identified, the adventitia has a profound influence on the population of intimal and medial endothelial, macrophage, and smooth muscle cell function. Vascular injury and dysfunction of the perivascular adipose tissue promote expansion of the vasa vasorum, activation of fibroblasts, and differentiation of myofibroblasts. This regulates further biologic processes, including fibroblast and myofibroblast migration and proliferation, inflammation, immunity, stem cell activation and regulation, extracellular matrix remodeling, and angiogenesis. A debate exists as to whether the adventitia initiates disease or is just an important participant. We describe a mechanistic model of adventitial function that brings together current knowledge and guides the design of future investigations to test specific hypotheses on adventitial pathobiology. (Am J Pathol 2020, 190: 520-534; https://doi.org/10.1016/j.ajpath.2019.10.021)
\end{abstract}

The blood vessel wall is composed of three layers. The intima comprises the innermost, the media comprises the middle, and the adventitia comprises the outermost of the blood vessel. ${ }^{1}$ The size and structure of each layer of the blood vessel, including the adventitia, varies with the size and function of the specific vessel, both in the arterial and venous circulation. The adventitia is surrounded by a special type of adipose tissue termed perivascular adipose tissue (PVAT). PVAT may not be easily demarcated from the adventitia so some investigators do not, whereas others suggest that the PVAT may be a fourth anatomic layer of the vessel wall. ${ }^{2,3}$ However, as we will review, the PVAT is an important functional layer.

The physiological function of the adventitia was believed to be limited to providing structural support to the blood vessel wall, transporting oxygen and nutrients to the adventitia and outer media of large vessels, and maintaining sympathetic innervation of the vessel wall. ${ }^{4}$ These were generally considered physiological static functions and were not believed to play a dynamic role in vascular development and vascular injury and repair. The latter was attributed primarily to the following: i) the endothelial cells (ECs) of the intima, which are located at the blood-vessel wall interface, forming a thromboresistant surface and a selective permeability barrier that becomes dysfunctional in disease; ii) macrophages entering the wall at the luminal side; and iii) smooth muscle cells (SMCs) of the media, which were

Disclosures: None declared. 
shown to dedifferentiate and change into several phenotypes in the face of disease. Critical to this thinking is the notion that the vascular inflammatory response seen in all vascular diseases is initiated exclusively at the luminal surface of the blood vessel. However, recent studies have shown that our thinking about the adventitia, especially its cellular composition, function, and response to injury, must be revised.

We will present evidence derived from in vivo and in vitro experiments and from human studies to suggest that the cells of the adventitia regulate (Table 1) the structure and function of all three layers of the vascular wall. Presentation of this evidence will focus on the following: i) activation of adventitial fibroblast (F) subtypes and their differentiation into myofibroblasts (MFs), ii) the adventitia as a niche for stem and progenitor cells, iii) the growth of the vasa vasorum (VV) through angiogenesis and vasculogenesis, and iv) the influence of the $\mathrm{VV}$ in regulating its own bloodendothelial wall interface, which is an important gateway into the vessel wall and modulates inflammatory cell traffic, immunosurveillance, and access of systemic circulating biologic factors into the vessel wall.

A critical gap in knowledge is to understand whether the adventitial changes seen in vascular disease indicate that disease is initiated and sustained by the adventitia and/or whether adventitial dysfunction is simply a manifestation of a passive secondary process once disease conditions have been established in the intima-media. This has led to an intriguing concept, that of the outside-in hypothesis, ${ }^{5}$ which considers the adventitia to be a sensor of vascular wall disruption and dysfunction and an early responder and activator of the blood vessel response to injury. ${ }^{6}$ Initially, this notion gained some prominence as a viable hypothesis to explain vascular restenosis occurring after percutaneous coronary angioplasty. ${ }^{7}$ Our review of the literature suggests that there is considerable evidence to support aggressive study of the vascular adventitia in health and disease to test all aspects of the outside-in hypothesis.

\section{Structure of the Healthy Adventitia}

The adventitia is separated from the media by the external elastic lamina. In large vessels, the media and the adventitia are easily distinguishable, whereas in small vessels, the media is thin and the external elastic lamina is not well developed and so adventitial cells are much closer to medial and intimal tissue.

The adventitia contains several cell types (Table 1) in contrast to the media, which contains predominantly SMCs. These adventitial cells include numerous fibroblasts, some of which may become MFs on activation, a small number of SMCs, adipocytes, pericytes, and resident immune cells, including macrophages, dendritic cells, mast cells, T cells, and B cells. The adipocytes are most prominent in the PVAT. ${ }^{2}$ In addition, three important components of the adventitia include the VV microvessels, lymphatics, and perivascular nerves (PVNs). The VV are located in the adventitia and outer media of larger arteries. They establish a bloodendothelial interface within the adventitia, which plays an essential regulatory role in delivering oxygen and nutrients, in inflammation and immunosurveillance, and in delivering circulating stem/precursor cells. The adventitial cells are randomly distributed within an extracellular matrix (ECM) rich in collagen fiber bundles, elastic fiber nets, proteoglycans, fibronectin, and tenascinc. ${ }^{6}$ Adventitial fibroblasts, the most common cell type in the adventitia, produce the ECM fibers, including types I and III fibrillar collagen. ${ }^{6}$ Type I is less extensible, helps bear the pressure load, and is an important factor in vascular stiffness. ${ }^{4,8}$ The larger adventitial collagen fibers show more diverse orientation under biaxial strain when compared with the smaller medial fibers, which are aligned circumferentially when they are stretched. ${ }^{9}$ Studies of in situ coronary arteries show the adventitia to be stiffer than the media in a longitudinal direction while the media takes up the load in the circumferential direction. ${ }^{9}$ Thus, in physiological states, the media bears most of the load, whereas the adventitia remodels its collagen structure to protect the vessel wall from overstretching at high pressures. ${ }^{9-11}$

The adventitia is likely involved in the production and release of biologic factors and nutrients that help sustain and regulate the structure and physiological function of the entire blood vessel wall. However, because the maintenance of the vessel wall is stable and normally does not involve measurable changes, studies to interrogate these homeostatic functional activities of the normal nonstressed adventitia in adult vessels have not been well characterized, except in investigating its structural role in regulating responses to vessel wall stretch. The large elastic arteries absorb ventricular pulse pressure to dampen the propagation of the pulse pressure gradient, and the adventitia is involved through regulating vasomotion in these biomechanical forces. $^{12}$

Detailed morphologic studies have shown that the adventitia itself may have layers or compartments. These are difficult studies to perform and interpret because there are no specific demarcations to identify where one compartment ends and another begins within the adventitia. Witter et $\mathrm{al}^{13}$ observed that in cats, dogs, and pigs, the structure of adventitia consists of an inner, compact layer, in which there are more adventitial elastic fibers in muscular arteries and fewer in elastic arteries, and an outer layer of loose connective tissue. Chen et $\mathrm{al}^{11}$ recently observed in porcine coronary arteries that elastin and collagen fibers form concentric, densely packed fiber sheets in the inner adventitia, and that collagen fibers become thicker and more randomly distributed closer to the outer adventitia. 
Table 1 Cells of the Vascular Adventitia

\begin{tabular}{ll}
\hline Cell & Behavior in normal physiology \\
\hline Fibroblasts & Most common cell type in the adventitia \\
& Quiescent cells \\
& Produce ECM, including types I and III \\
& collagen, proteoglycans, and fibronectin \\
& Phenotypic heterogeneous population
\end{tabular}

\section{Myofibroblasts}

Inflammatory cells (macrophages, dendritic cells, T cells, B cells, and mast cells)

Stem/progenitor cells

Vascular pericytes

SMCS
Not present in the adventitia

Resident population in the adventitia

Resident population in adventitia Located in stem cell niches regulated by adventitial factors and mechanotransduction pathways

Differentiate into endothelial cells, SMCs, hematopoietic cells, and local immune cells

Resident population in the adventitia

Mainly found in the media, but form a small part of the resident cell population of the healthy adventitia

Medial contractile cells regulating vasomotion
Behavior in disease

Subtypes undergo fibroblast activation, expressing different phenotypes expressing these features:

Proliferation and migration into intima-media

Production of growth factors, proinflammatory cytokines and chemokines, reactive oxygen species, adhesion molecules, and angiogenic factors

Altered ECM and metalloproteinase production for remodeling

A distinct subpopulation differentiates into myofibroblasts

A subpopulation of fibroblasts that express a specific phenotype:

Contractile elements that affect vascular tone Proliferation and migration into intima-media Production of proinflammatory cytokines, chemokines, and angiogenic factors

Altered ECM and metalloproteinase production for remodeling

Circulating and enter the adventitia through the endothelium and SMCs of the VV to join resident population

Proliferation and migration into intima-media

Secrete cytokines, chemokines, angiogenic factors, extracellular matrix proteins, and lymphokines

Contribute to intimal thickening and the development of atherosclerotic plaques

Immunosurveillance

Form aortic tertiary lymphoid organs

Resident stem/progenitor cells:

Activated by poorly understood stimuli

Contribute to VV expansion through

vasculogenesis

Proliferation and migration into intima-media Differentiate to SMCs, macrophages, endothelial cells, adipocytes, osteoblasts, and hematopoietic stem cells

Contribute to lymphocyte recruitment

Circulating stem/progenitor cells:

Enter the adventitia through the VV

Proliferate and migrate to the intima-media, where they differentiate into SMCs, macrophages, endothelial cells, adipocytes, osteoblasts, and hematopoietic stem cells

Give rise to mesenchymal stem cells, which can differentiate into mesoderm lineage cells Proliferation and migration into intima-media May participate in postinjury restenosis Medial SMCs may migrate to the inner adventitia and differentiate to generate a subpopulation of resident adventitial vascular progenitor cells that express SMC, myeloid, and hematopoietic progenitor-like properties and may migrate to intima-media 
Table 1 (continued)

\begin{tabular}{lll}
\hline Cell & Behavior in normal physiology & Behavior in disease \\
\hline Adipocytes & Resident population of the outer adventitia & $\begin{array}{l}\text { Increase local inflammation by producing adipo- } \\
\text { kines (cytokines) and chemokines }\end{array}$ \\
& and PVAT & Promote fibroblast activation \\
& vessel in a paracrine manner to affect the blood & Produce angiogenic factors that promote expan- \\
& tractile and anticontractile regulation & sion the VV \\
& May communicate with intima-media & \\
& The PVN network is located in the adventitia & Changes in vascular tone through poorly under- \\
and releases adrenergic, cholinergic, pepti- & stood mechanisms \\
PVNs & dergic, purinergic, and nitrergic neurotrans- & \\
& mitters that lead to SMC contraction or & \\
& relaxation via their actions on SMCs, ECs, or & \\
& other PVNs located in the adventitia & \\
\hline
\end{tabular}

EC, endothelial cell; ECM, extracellular matrix; PVAT, perivascular adipose tissue; PVN, perivascular nerve; SMC, smooth muscle cell; VV, vasa vasorum.

$\mathrm{Gao}^{14}$ also reported that the adventitia can be divided into two layers: an inner compact layer mainly composed of fibroblasts and an outer layer composed mainly of adventitial fat, alias PVAT, harboring adipocytes as the main cell type. PVAT may not be easily demarcated from the adventitia, so some investigators do not, whereas others go so far as to suggest that the PVAT may be a fourth layer of the vessel wall. ${ }^{2,3}$ The latter is not a popular opinion. In any event, from a functional point of view, the PVAT adipocytes do act in a paracrine manner to affect the blood vessel vasomotor tone and to act as both antiatherosclerotic and as proinflammatory cells synthesizing and releasing adipocytokines. The PVAT should be considered an important regulator of the physiology and pathophysiology of the vessel wall. $^{2}$

\section{Blood Supply in the Adventitia (VV)}

The adventitial VV is a specialized microvasculature (vessels within vessels) that, along with adventitial lymphatic $\mathrm{VV}$, transports nutrients and oxygen between the blood and the adventitia under physiological conditions. ${ }^{15}$ In the normal arterial wall, the VV represents the complete microvasculature of the wall. Anatomic data on aortic VV have been reported in several species, including pigs. ${ }^{16}$ Main vessels that enter the adventitia are distal branches of intercostal, lumbar, mesenteric, brachiocephalic, and coronary arteries that grow by angiogenesis during development. ${ }^{17}$ This has been confirmed by showing that experimental ligation of intercostal arteries results in necrosis of the media and some adventitial tissue in the aortic segment perfused by the ligated artery. ${ }^{17}$ In the adventitia, the vessels form small branches and three-dimensional branching networks localized primarily at the interface of the media and the adventitia. ${ }^{15}$ Histologic studies usually include arterioles, capillaries, and veins in density counts using standard histology and recently using antigen signatures for ECs, such as von Willebrand factor, CD31, and CD34. ${ }^{16}$ In vivo microcomputed tomography imaging has also been used to show the three-dimensional nature of the VV. ${ }^{18}$

Although nutrition of thin-walled normal blood vessels occurs through filtration from the lumen and diffusion through the intima and media, the $\mathrm{VV}$ is required for the transportation of nutrients and oxygen to the adventitia and the outer media, where the media is normally thick because of numerous lamellar units. Diffusion in the normal artery can extend for $0.5 \mathrm{~mm}$ from the luminal surface. ${ }^{19}$ Vessels with $\leq 29$ medial lamellar units do not have medial VV. ${ }^{20}$ Beyond a thickness of 29 lamellar units in the media, diffusion from the vascular lumen becomes insufficient to meet the nutritional needs of the media. ${ }^{19-21}$ Thus, in these arteries, the outer one-third to two-thirds of the media is perfused by $\mathrm{VV}$ penetrating into the media from the adventitia. The VV plays a crucial role in veins given that luminal oxygen and nutrient levels are low in these blood vessels in comparison to arteries. ${ }^{22}$ Therefore, the VV of veins penetrate closer to the intima than those of arteries, and the role of the $\mathrm{VV}$ of veins in venous disease remains unclear. $^{22}$

Little is known about adventitial lymphatic VV, especially in disease. They are in close proximity to the arterial $\mathrm{VV}$ and appear to be, in contrast to the arterial VV, more dense in the infrarenal abdominal aorta. ${ }^{23}$

\section{Nerve Supply in the Adventitia}

Tissue perfusion and vascular resistance are regulated by vasoconstriction and vasodilation of arteries and arteriolar networks through SMC contractility. The processes involved are as follows: i) molecules secreted by ECs, which have either vasoconstrictive or vasodilatory activity; ii) perivascular innervation in the $\operatorname{adventitia}^{24}$; and iii) paracrine influences from cells in the PVAT, such as adipocytes acting directly on SMCs or via ECs to regulate vasomotion. ${ }^{2}$ The contractile SMCs are targeted by vasoactive molecules, such as endothelin, nitric oxide, prostaglandin, angiotensin (Ang), and endothelium-derived 
hyperpolarization factor. The PVN network is located in the adventitia and releases adrenergic, cholinergic, peptidergic, purinergic, and nitrergic neurotransmitters that lead to SMC contraction or relaxation. Different vessels and vascular beds show heterogeneity in anatomy, quantity, and composition of PVNs and do not make direct contact with SMCs or ECs. PVNs do not penetrate the media, irrespective of the number of SMC layers present. ${ }^{25-27}$ Once the neurotransmitters are released, they diffuse to receptors located on SMCs, ECs, and other PVNs. Neurotransmission from PVNs can evoke distinct responses from ECs subsequent to acting on SMCs via myoendothelial junctions. ${ }^{24}$ Thus, the adventitia signals the medial SMCs to help regulate short-term contraction.

Sympathetic nerves account for the largest proportion of innervation in the resistance vasculature. Activation of sympathetic PVNs causes vasoconstriction, whereas activation of sensory or parasympathetic PVNs causes vasodilation. Perivascular parasympathetic and nitrergic nerves are present on many vessels.

Perivascular sympathetic adrenergic nerves arise from postganglionic efferent axons, with their cell bodies located in the paravertebral ganglia. ${ }^{28}$ Efferent sympathetic axons form a plexus within the adventitia ${ }^{29}$ and generally follow the arterial supply, entering the tissue along feed arteries, coursing along arterioles, and terminating along the precapillary arterioles. ${ }^{30}$

There is not a single site of neurotransmitter release from sympathetic nerves. Instead, neurotransmitters are released from varicosities along the efferent axons and results in dispersed actions of neurotransmitter molecules as they diffuse to their receptors.

\section{Adventitia as a Stem/Progenitor Cell Niche}

After cell division, stem cells produce one stem cell and one differentiating cell to maintain tissue homeostasis. All three layers of the vessel wall have resident stem cells present that are important in vascular development, repair, and remodeling. Medial SMCs may differentiate to macrophages, osteogenic and chondrogenic cells, and adipocytes. The macrophages are described as macrophage-like because they express only some macrophage markers and thus may not have all the functions of traditional macrophages. Stem cell markers in general include stem cell antigen-1 (Sca-1), c-kit, fetal liver kinase 1, CD34, CD124/90, CD68, CD44, and SOX, although there are to date no unique cell surface markers to detect vascular stem/progenitor cells. ${ }^{31}$ Several types of stem/progenitor cells have been identified in the adventitia, including SMC progenitor cells, endothelial progenitor cells, mesenchymal stem cells (MSCs), and myeloid progenitor cells. Thus, it is clear that vascular wall cells show plasticity, as determined by cell surface markers and gene expression. How these observed cells function with respect to mature differentiated cells of the same type is poorly understood. Much of the plasticity is dependent on unknown factors and poorly defined cellular environments. How welldefined in vitro conditions mimic in vivo conditions in the vessel wall is also poorly understood. The overall research objective now is to identify the origin of these cells, describe their function in the normal physiological niche, and understand how they are activated during repair and remodeling after injury.

The adventitia is a rich source of stem and progenitor cells within an extracellular environment referred to as a stem cell niche, located at the medial-adventitial interface. These niches are usually loosely defined anatomic areas of tissues, which consist of stem cells, progenitor cells, and precursor cells dispersed in a microenvironment of ECM rich in factors that maintain the cells, allow for self-renewal, and allow for subsequent differentiation. These cells function in the adventitia and are a source of cells for the media and intima because of their ability to migrate into these layers. Although it is not well studied or understood, it is likely that some unknown dysfunction in the biochemistry of the niche and perhaps disruptions in mechanotransduction related to the biomechanical forces that the blood vessel wall is exposed to activate these cells. More importantly, they are active during a response to injury by expanding the $\mathrm{VV}$, promoting inflammation, and populating the media and intima. Resident cells in the area of the interface of the media and adventitia express stem cell surface markers $\mathrm{CD} 34^{+}, \mathrm{Sca}-1^{+}, \mathrm{c}^{-k i t}, \mathrm{~F} 1 \mathrm{k} 1^{+}$, and $\mathrm{CD} 140 \mathrm{~b}^{+}$. The niche is a zone of sonic hedgehog signaling in the adventitia close to the media. These cells do not appear to originate from bone marrow ${ }^{32}$ or cardiac neural crest. $^{31}$ Zengin et $\mathrm{al}^{33}$ showed that this zone, which they referred to as a vasculogenic zone, contained endothelial progenitor cells and stem cells that could differentiate into ECs and hematopoietic and local immune cells. In a variety of animal models, adventitial-derived cells have been identified in the media and even in the neointima. Progenitor cells expressing cell surface markers Sca-1, CD34, and c-kit were found in the adventitia of atherosclerotic lesions. ${ }^{34}$ Progenitor cells in the adventitia of apolipoprotein $\mathrm{E}$ knockout mouse $\left(\mathrm{ApoE}^{-/-}\right.$) contribute to atherosclerosis of vein grafts because the cells are able to differentiate into SMCs. ${ }^{32,35}$ It is likely that some of these cells are adventitial progenitor cells. ${ }^{35}$ However, some may simply be mature adult cells of the adventitia that differentiate and migrate into the media and intima as part of vessel wall remodeling because it is well known that vascular wall cells have the ability to differentiate and change phenotype.

Majesky et $\mathrm{al}^{36}$ showed that murine medial SMCs may migrate to the inner adventitia and differentiate to generate a subpopulation of resident adventitial vascular progenitor cells that express SMC, myeloid, and hematopoietic progenitor-like properties. These progenitor cells express the cell surface markers Sca-1 and CD34. K1f4 is required for this SMC reprogramming, which may generate 
macrophages, endothelial-like cells, SMCs, and, to a lesser extent, adipocytes and osteoblasts.

A limited study reported by Michelis et $\mathrm{al}^{37}$ showed that the cell surface marker CD90 was useful in identifying adventitial MSCs in human adult large- and medium-sized arteries. These were described as relatively rare and located specifically in the adventitia.

Vascular pericytes give rise to MSCs, which can differentiate into mesoderm lineage cells. ${ }^{38,39}$ However, distinct MSCs expressing CD $34^{+}, \mathrm{CD} 31^{-}, \mathrm{CD} 146^{-}$, and $\mathrm{CD} 45^{-}$ are also found in the perivascular location and are distinct from pericytes. Tigges et $\mathrm{al}^{40}$ used a femoral artery wire injury model to show that adventitial pericyte-like progenitors, or MSCs, participate in postinjury restenosis and appear in the neointima after injury. These pericytes expressed pericyte markers NG2, platelet-derived growth factor-receptor- $\beta$, and CD146. After injury, some of these cells also express MSC-like phenotype markers, including CD90 and CD29. These cells are resident adventitial cells and are not derived from the bone marrow. ${ }^{40}$

The adventitia of the postnatal murine aorta is also a source of hematopoietic progenitor/stem cells that are under the broad immunophenotype of Sca- $1{ }^{41}$ Vascular hematopoietic reconstitution is a rare event; however, it is upregulated in the proatherosclerotic model $\mathrm{ApoE}^{-1-}$ deficient mice. The potential importance of an adventitial source of Sca- $1^{+}$hematopoietic progenitor cells is unknown in both normal vascular health and disease.

Sca- $1^{+} \mathrm{CD}_{4} 5^{+}$adventitial macrophage progenitor cells have been identified in adult C57BL/6 mice, which contained a proliferative $\left(\mathrm{Ki}-67^{+}\right) \mathrm{Lin}^{-} \mathrm{c} \mathrm{Kit}{ }^{+} \mathrm{CD} 135^{-} \mathrm{CD} 115^{+}$ $\mathrm{CX}_{3} \mathrm{CR} 1^{+} \mathrm{Ly}_{6 \mathrm{C}}{ }^{+} \mathrm{CD} 116^{-}$subpopulation with a macrophage progenitor phenotype. ${ }^{42}$ These cells were not replenished from bone marrow or spleen. Adventitial Sca$1^{+} \mathrm{CD} 45^{+}$cells also possess vasculogenic and angiogenic activities and may thus be a source of $\mathrm{VV} .{ }^{43}$

Mekala et $\mathrm{al}^{44}$ demonstrated that fetal liver kinase 1 -positive $\mathrm{CD} 4^{+}$stem cells resident in the vascular adventitia, including that of coronary arteries, are a source for generating mouse and human cardiomyocytes after myocardial infarction. ECs and macrophages support this novel process. However, future research will have to confirm that the adult heart can renew functioning cardiomyocytes through endogenous regeneration mechanisms, and that these new myocytes can integrate into the myocardial syncytium and promote safe electrophysiologic conduction.

\section{Adventitial VV in Disease}

Although the adventitial VV has been primarily studied in atherogenesis models, other areas, such as vascular aneurysms, hypertension, and vasculitis, have been considered and deserve more adventitial research.
The amount of the adventitial VV differs along segments of the aorta, being more dense in the aortic arch, becoming less dense in more distal segments, and least dense in the infrarenal aorta. ${ }^{23}$ Because the prevalence of aortic disease varies at different segments of the aorta, these differences may be an important factor in the predisposition of disease. For example, atherosclerotic aneurysms are at least three times more frequent in the abdominal aorta in comparison to the descending thoracic aorta. ${ }^{45}$ Furthermore, almost all abdominal aortic aneurysms (AAAs) occur in the infrarenal region of the aorta in humans. ${ }^{23}$

The adventitia appears to be important in the pathogenesis of AAAs, at least in part during initiation and during the progression of aneurysm formation. Early macrophage infiltration of adventitia is seen in AngII-induced murine aneurysm. ${ }^{46}$ Tanaka et al ${ }^{47}$ found that chronic hypoperfusion of the VV can support the development of infrarenal AAAs. Furthermore, the authors studied human aorta samples of patients undergoing surgery for repair of infrarenal AAA or bilateral common iliac artery aneurysm, and found that adventitial VV were stenotic and that the aortic wall was ischemic in both small and large aneurysms ${ }^{47}$ These findings, however, cannot distinguish between a primary and a secondary event.

Because approximately $65 \%$ to $70 \%$ of cases of aortic dissection occur in the ascending and descending thoracic aorta, it is postulated that the dense distribution of $\mathrm{VV}$ in this area of the aorta may make it more likely that a rupture and hematoma occur in the $\mathrm{VV}$, leading to a dissection. ${ }^{23}$ However, neither the frequency nor the nature of the rupture is known. This proposed pathogenesis may, however, help explain aortic dissections where no internal tear of the intima-media is found.

The interface between the aortic media and adventitia is prone to dissection in some genetic conditions, such as $\mathrm{Col} 3$ $A I$-deficient mice ${ }^{48}$ and in biglycan (BGN) knockout male mice homozygous for a BGN null mutation bred into a BALB/CA background. ${ }^{49}$ This is unlike the dissection that occurs in human aortas, which is usually between the outer one-third and the inner two-thirds of the media. It is likely that in BGN knockout mice, this is because BGN is prominent in the adventitia and BGN deficiencies may result in changes in collagen fibrils, leading to reduced tensile strength and dissection.

In a rat model of intracranial aneurysm and rupture in which aneurysms are induced by increasing the hemodynamic force to which bifurcation regions of intracranial arteries are subjected, Miyata et $\mathrm{al}^{50}$ found that the number of VV was significantly higher in ruptured versus nonruptured areas. Their data suggested that fibroblast growth factor 2 may promote VV growth, which results in new macrophages entering the adventitia to promote vascular damage and subsequent rupture.

In humans, there is accumulating evidence that links the expansion of adventitial VV to neointima formation and atherosclerotic plaque development and growth. ${ }^{15,51}$ 
Significant correlations between the numbers of left carotid VV in the adventitia and left carotid intima-media thickness, an early predictor of plaque development, have also been observed. ${ }^{52}$ These correlations have not been observed in the right carotid artery. These differences may provide a partial explanation as to why atherosclerotic lesions develop earlier in the left carotid than in the right.

Inhibition of plaque neovascularization has been observed to slow plaque growth by reducing the accumulation of macrophages in the plaque. ${ }^{19,53}$ Although the noninflamed human coronary arteries and aortas do not become highly vascularized, in atherosclerosis, the plaque forms a dense capillary plexus, at least in part, by angiogenesis derived from adventitial and/or outer medial VV. The pathogenesis of these new VV may be due to secretion of angiogenic factors by macrophages and SMCs in the plaque. Fibroblast growth factor 2 is an important angiogenic factor expressed by VV. In addition, the plaque becomes locally ischemic because the intima thickens and diffusion of oxygen and nutrients is disrupted, and this promotes angiogenesis as well. ${ }^{15}$ It is also possible that vasculogenesis is also occurring by resident stem/precursor cells in the adventitia and/or progenitor cells derived from medial SMCs, which differentiate into ECs and SMCs.

Because inhibition of plaque neovascularization has been shown to slow plaque growth, researchers have aimed to develop interventions that limit the expansion of the VV using angiogenesis inhibitors. Hytönen et $\mathrm{al}^{54}$ found that blocking adventitial neovascularization in rabbit aortas using soluble vascular endothelial growth factor (VEGF) receptor-1 and VEGF receptor-2 can serve as a novel strategy to reduce in-stent restenosis by reducing the number and size of adventitial VV. Blocking the function of VEGF receptor-2 in hypercholesterolemic $\mathrm{ApoE}^{-1-}$ mice that received human caval vein interpositions in the carotid artery prevented intraplaque hemorrhage. This likely occurred by enhancing the maturation of newly developed VV primarily in the adventitia. ${ }^{55}$

Coronary arteries of hypercholesterolemic pigs show that the adventitial VV begins to proliferate before aortic wall thickening and that the proliferation is, in turn, preceded by infiltration of inflammatory cells into the adventitia, which release, for example, VEGF-A, promoting the growth of new VV. ${ }^{56}$ These new capillaries, often leaky and poorly organized, can lead to small hemorrhages in a growing atherosclerotic lesion and may rupture from within, generating vulnerable plaques, which, in turn, may promote fibrous cap rupture. The adventitial lymphatic VV have also been implicated in the pathogenesis of atherosclerosis. ${ }^{57}$ The VV may play a role in providing a gateway for circulating transport of mobilized progenitor cells to enter the intima-media, where they differentiate into SMCs and enhance intimal thickness and plaque growth. ${ }^{15}$ Lymphocytes enter the adventitia via the VV, and thus neovascularization plays a key role in enhancing and regulating the immune response in atherosclerotic plaques. $^{56}$

The VV appears to play a critical role in determining the success of revascularization in cardiac patients undergoing coronary artery bypass surgery. During the procedure of harvesting and anastomosing the human saphenous vein into the coronary circulation, the adventitia is damaged. In the veins, which carry low levels of oxygen and nutrients, the VV run deeper into the media and some may, in fact, terminate in the venous lumen. Thus, damage and disruption of the VV deprive the venous wall from receiving adequate oxygen, nutrients, and factors that protect it from injury and aid in repair. The loss of adequate VV may promote hyperplasia and atherosclerosis, two serious complications of coronary artery bypass surgery. ${ }^{58}$ The loss will also deprive the venous wall with the benefits of the PVAT because it is also disrupted and damaged.

Kawasaki disease is a vasculitis affecting primarily children and infants. ${ }^{59}$ In a model in which Kawasaki disease is induced in mice, growth of the VV occurs before evidence of vasculitis. ${ }^{59}$ In this model, the VV became a conduit for inflammatory cells that appeared first in the adventitia and eventually resulted in a panvasculitits.

\section{Cell and ECM Changes in the Adventitia in Disease}

Fibroblasts and MFs are thought to regulate remodeling of the adventitia during pathologic conditions, such as hypertension, hypoxia, and atherosclerosis. ${ }^{60}$ Fibroblasts in general have been shown to be composed of heterogeneous subpopulations of cells with varying morphologic and functional phenotypes. ${ }^{61}$ The fibroblasts may also exhibit tissue-specific gene expression. There are several studies that support an important concept that adventitial fibroblasts may act as adipogenic progenitors. ${ }^{62}$ This is still controversial with a sound alternate hypothesis that the precursors are pericytes and vascular SMCs. ${ }^{63}$ Normally, fibroblasts are in a quiescent, undifferentiated state; however, in response to injury and stressors, they undergo fibroblast activation, in which they show prominent proliferation, alter their production of ECM, and increase their production of proinflammatory cytokines, chemokines, and adhesion molecules. After their activation, some fibroblasts differentiate into MFs and SMCs. ${ }^{6,64,65}$ MFs are described as activated differentiated fibroblasts with features similar to SMCs. ${ }^{66}$ They possess secretory features similar to fibroblasts while also containing bundles of actin microfilaments with associated contractile proteins. ${ }^{64}$ They are well studied and shown to be instrumental during normal tissue repair in processes such as skin wound healing and tissue fibrosis. ${ }^{64}$ Hinz et $\mathrm{al}^{61}$ list myofibroblast modulating factors, both inducing and suppressing, in a recent review. These include transcription-regulating factors, epigenetic regulators and miRNAs, growth factors, cytokines, ECM, 
ECM-modulating proteins, physical factors, and membranebound and surface-expressed proteins.

Fibroblast populations are composed of several phenotypically diverse subpopulations. ${ }^{64}$ The adventitia is similarly composed of numerous fibroblast subtypes that differ in morphology, size, and behavior during injury and disease. ${ }^{64,67}$ For example, Das et $\mathrm{al}^{68}$ observed selective expansion of hypoxia-induced proliferative adventitial fibroblast subpopulations in pulmonary arteries of calves. These subpopulations showed phenotypic and functional differences compared with other fibroblasts in the adventitia.

In atherosclerosis models, $\mathrm{Xu}$ et $\mathrm{al}^{60}$ described activation of adventitial fibroblasts in the early stages of atherogenesis in the $\mathrm{ApoE}^{-} /^{-}$mouse. During vascular remodeling, collagen I expression is reduced, whereas collagen III and procollagen $\alpha-1$ expression levels are increased. Furthermore, hypertensive animals have increased amounts of collagen in the adventitia in comparison to nonhypertensive animals. ${ }^{69}$ In pulmonary hypertension, the fibroblasts in the adventitia secrete fibronectin, tenascin, and osteopontin to remodel the matrix. Matrix metalloproteinases and tissue inhibitors of metalloproteinases are also secreted to help remodeling and facilitate cell migration through the adventitial matrix. ${ }^{70} \mathrm{Li}$ et $\mathrm{al}^{71}$ reported that adventitial fibroblasts undergo metabolic reprogramming during pulmonary hypertension. This reprogramming involves increased reliance by the fibroblast on aerobic glycolysis relative to oxidative phosphorylation. It is suggested that this supports anabolic reactions required for proliferation and inflammation. ${ }^{71}$

Mechanistic studies are now revealing how adventitial cells regulate their pathobiologic effects. Dutzmann et $\mathrm{al}^{72}$ showed that increased proliferation of adventitial fibroblasts as well as a robust expansion of the adventitial layer are activated by sonic hedgehog and its downstream protein smoothened, which were expressed more prominently in injured arteries of C57BL/6 mice in comparison to noninjured mice arteries. Moreover, combined stimulation of sonic hedgehog and platelet-derived growth factor-BB increased the proliferation and migration of human adventitial fibroblasts in vitro. ${ }^{72}$ The supernatant of these activated fibroblasts contained high levels of proinflammatory cytokines as well as growth factors, which also strongly induced the proliferation of SMCs and promoted neointima formation. ${ }^{72}$ Another signaling pathway identified in adventitial fibroblasts is the elevated expression of NADPH oxidase 4, which promotes the production of reactive oxygen species and likely contributes to hypertensive vascular remodeling. ${ }^{73}$ Barman et $\mathrm{al}^{74}$ reported that the overexpression of NADPH oxidase 4 stimulates the migration and proliferation of adventitial fibroblasts and is furthermore required for ECM gene expression. NADPH oxidase 4 has also been shown to modulate collagen production by fibroblasts both in vivo and in vitro. ${ }^{75}$

The phenotypic differentiation of fibroblasts into MFs in the adventitia appears to contribute to intimal thickening and luminal stenosis because MFs are capable of migrating through the media and into the intima while secreting and organizing alterations in the ECM. ${ }^{76}$ The extent of MFs' contribution to neointimal formation, however, is still controversial, ${ }^{77}$ especially in angioplasty models where the adventitia is stretched and restenosis follows. ${ }^{78}$ The accumulation of MFs in the adventitia produces collagen, fibronectin, tenascin, and elastin, which contributes to changes in vascular tone as well as the structure of the blood vessel. ${ }^{70,79}$ Chang and colleagues ${ }^{80}$ compared the nanomechanics and ultrastructure of the internal mammary artery adventitia in patients with low and high arterial stiffening, measured as pulse wave velocity. The internal mammary artery adventitia of patients with a high degree of arterial stiffness had significantly more collagen fibers with smaller fibril diameters compared with patients with a low degree of arterial stiffening. This may be due to activation of resident fibroblasts that differentiate into MFs during response to injury.

Both mechanical and chemical factors regulate fibroblastMF differentiation. ${ }^{61}$ These steps are described by Coen et $\mathrm{al}^{64}$ in a detailed review. The first step in the differentiation process is the activation of fibroblasts by cytokines released from inflammatory cells and ECs after tissue injury. They refine the steps by including a proto-MF phenotype, which continue to release several ECM components and organize into a mechanically supportive structure, which ultimately produces a contractile force. The increased stress within the ECM as a result of proto-MF activity promotes the fibroblast-MF differentiation process, which is characterized by increased expression of $\alpha$-smooth muscle actin. However, $\alpha$-smooth muscle actin is also a marker for SMCs and activated fibroblasts; thus, additional markers specific for MFs are necessary. Transforming growth factor- $\beta$ and reactive oxygen species may modulate the fibroblast differentiation.

PVAT is a special type of adipose tissue composed of adipocytes, immune cells, and fibroblasts, which closely surround the adventitia. Little was known about PVAT because previously, it was typically removed from traditional blood vessel studies as it was considered a nonvascular tissue, which mainly served to provide mechanical support to the blood vessel. Nevertheless, it has since been discovered that PVAT regulates vascular tone, both through contractile and anticontractile regulation, vessel pathobiology in inflammation, angiogenesis, neointimal formation, and vascular fibrosis. ${ }^{81}$ PVAT dysfunction is promoted by vascular injury, aging, obesity, and metabolic syndrome, and may impact adventitial remodeling during the early stages of vascular injury. ${ }^{82}$ Communication between cells in the PVAT and cells residing in the other layers of the blood vessel wall occurs through the $\mathrm{VV}$ or through paracrine signaling. ${ }^{83}$

PVAT dysfunction can be induced by obesity in minipigs with left carotid vascular injury. ${ }^{82}$ This results in increased fibroblast proliferation and differentiation, as well as increased local inflammation characterized by the 
accumulation of proinflammatory macrophages, leptin, and proinflammatory cytokine IL-1 $\beta$ and IL-18. These changes have been shown to be induced by the nod-like receptor protein 3 inflammasome pathway. Okamoto et $\mathrm{al}^{84}$ also observed that after balloon overstretch injury of porcine coronary arteries, inflammation and increased MF proliferation occurred not only in the adventitia but also in the PVAT surrounding the injured artery. These findings have led to the hypothesis that the inflammatory cells in PVAT contribute to vascular remodeling by recruiting and/or promoting the proliferation of adventitial MFs. ${ }^{83}$

The adventitia is considered to be involved in the pathogenesis of hypertension through regulation of vasomotion of the resistance arterioles and changes in the ECM. This occurs by promoting VV growth, inflammatory cell accumulation, activation of adventitial fibroblasts, and increased secretion of matrix, especially collagen and fibronectin. For example, in-depth studies are beginning to explore the role of adventitial matrix cells in the remodeling of the adventitia in hypertension. Studies on spontaneous hypertensive rats have shown that fibronectin domain containing 5 attenuates fibroblast transformation to MFs as well as nod-like receptor protein 3 inflammasome activation in spontaneous hypertensive rat hypertension. ${ }^{85}$ Abnormal mitochondrial fission, which has been observed in various cardiovascular diseases, has also been suggested to play a role in adventitial fibroblast reprogramming and phenotypic changes. ${ }^{86}$ Huang et al, ${ }^{86}$ using cultured cells from AngII-induced hypertensive mice, showed that reducing mitochondrial fission by inhibiting heat shock protein 90 successfully decreased the proliferation and migration of adventitial fibroblasts, as well as their transformation into MFs. These are early studies; however, the authors suggest that heat shock protein 90 may therefore serve as a potential target to mitigate remodeling of the adventitia.

\section{Immune Functions in the Adventitia}

Immune cells, such as macrophages, dendritic cells, T cells, and, to a lesser extent, B cells form a small part of the resident cell population in the normal, noninflamed artery adventitia. ${ }^{87,88}$ However, innate and adaptive immunity are active in the pathogenesis of atherosclerosis, and inflammation has been positively associated with the severity of atherosclerosis. $^{87,89-91}$ Sakamoto et $\mathrm{al}^{92}$ reported that adventitial inflammation may contribute to the development of atherosclerotic plaques in specific regions of the aorta. They compared the morphology of the aortic arch, descending aorta, and abdominal aorta in wild-type and ApoE ${ }^{-} /{ }^{-}$C57BL/6J mice that were fed with standard chow for 16,32 , and 52 weeks. They found not only that plaque formation progressed with the duration of the experiment, but also that the number of macrophages, $T$ cells, and microvessels was significantly higher in the adventitia of the abdominal aorta of the $\mathrm{ApoE}^{-} /^{-}$at 52 weeks. Interestingly, these numbers of inflammatory cells positively correlated with plaque formation and collagen deposition, but negatively correlated with elastin content in the aortic wall, suggesting that matrix repair was prominent in vascular remodeling. Moos et $\mathrm{al}^{89}$ described significant adventitial lymphocyte accumulation in the aortas of aging $\mathrm{ApoE}^{-/-}$ mice fed standard chow diets.

Murine studies have revealed that inflammatory cells accumulate in the aortic adventitia adjacent to atherosclerotic lesions forming organized structures known as aortic tertiary lymphoid organs (ATLOs). ${ }^{48}$ The presence of lymph vessels and high endothelial venules in ATLOs allows for further recruitment and migration of lymphocytes from the blood vessel. ${ }^{93}$ ATLOs contain large numbers of $\mathrm{T}$-regulatory cells, including naïve $\mathrm{T}$ cells that are recruited to ATLOs, where they are converted to T-regulatory cells. ${ }^{94}$ Moreover, genes involved in somatic hypermutation of the B-cell receptor and B-cell memory generation have been discovered to be expressed at significant levels in ATLOs. ${ }^{94}$ This suggests that ATLOs are involved in both the innate and adaptive immune responses observed in atherosclerosis ${ }^{95}$ However, the cause and effect mechanisms are not currently understood.

Akhavanpoor et $\mathrm{al}^{96}$ demonstrated the presence of ATLOs in the adventitia of human atherosclerotic coronary arteries. They used a classification system for these human ATLOs based on a murine classification system developed by Gräbner et al. ${ }^{97}$ In this system, ATLOs are assigned to one of the three stages (I to III) based on the type and quantity of inflammatory cell aggregates they contain. Stage I ATLOs predominantly contain T cells, stage II ATLOs are composed of distinct Band T-cell areas, and stage III ATLOs contain separate B- and $\mathrm{T}$-cell areas and ectopic germinal centers. Immunoenzyme staining of human coronary artery samples found that the stage of tertiary lymphoid organs (TLOs) was significantly positively associated with lesion size, plaque instability, and rupture. ${ }^{96}$ They found in their human population that most of the patients with severe coronary artery disease had stage II TLOs, whereas all samples from patients who experienced fatal myocardial infarction had stage III TLOs. The latter were also associated with a loss of cellular and structural composition of the media next to a TLO as well as invasion of T and $\mathrm{B}$ cells into the media and intima adjacent to the atherosclerotic lesion.

For unknown reasons, with increasing age, there is an increased quantity of inflammatory cells in the adventitia. In aged $\mathrm{ApoE}^{-l-}$ mice, adventitial ATLOs develop only in relation to lesion sites, especially in the abdominal aorta. This appears to be triggered by medial SMCs present beneath intimal plaques in abdominal aortae, which become activated through lymphotoxin $\beta$ receptor. ${ }^{97}$ This, in turn, causes them to express CXCL13 and chemokine (C-C motif) ligand 21, two lymphorganogenic chemokines, triggering the development of adventitial ATLOs. On the other hand, interrupting signaling of the lymphotoxin $\beta$ receptor significantly disrupts the structure and maintenance of ATLOs. ${ }^{97}$ An interesting suggestion is that because SMCs 
along the length of the aorta may be differentially derived from distinct embryonic lineages, ${ }^{37}$ they may express functional differences in different areas of the aorta. This needs to be investigated in comparison to the localization and formation of ATLOs. Zhang et $\mathrm{al}^{93}$ also identified IL-7 receptor as a central gene involved in promoting cytokinecytokine receptor interaction and chemokine signaling pathway, two pathways required for the recruitment of leukocytes into inflammatory sites in aged $\mathrm{ApoE}^{-1-}$ mice.

Local and systemic inflammation triggers neovascularization of the adventitial $\mathrm{VV}$ as well as enhanced vascular permeability, which subsequently allows more inflammatory cells to enter the plaque through the leaky, newly formed vessels. In atherosclerotic mice, the VV have been observed to be the primary means of transportation for leukocytes into atherosclerotic plaques. ${ }^{98}$ In addition, inhibition of VV expansion in atherosclerotic arteries has been observed to successfully reduce the accumulation of inflammatory cells in plaques as well as delay their progression. ${ }^{53,99}$ Using a rat balloon injury model, Li et al ${ }^{100}$ found that adventitial fibroblasts produce VEGF, which promotes formation of adventitial $\mathrm{VV}$, in turn increasing macrophage accumulation in the adventitia and contributing to neointima formation. Conversely, blocking VEGF function diminished angiogenesis and neointima formation in endothelial denudation models. ${ }^{100}$ Because inflammation and expansion of the VV tend to feed each other in a vicious cycle, regulating one of these two may serve as a means to control the other and thus decrease plaque progression and subsequent cardiovascular events.

In addition to contributing to VV expansion, a large body of evidence suggests that activated adventitial fibroblasts significantly contribute to inflammation in the adventitia. Specifically, adventitial fibroblasts produce reactive oxygen species in the early stages of vascular disease, which, in turn, promotes neovascularization in the adventitia by increasing the expression of adhesion molecules, ultimately allowing for further leukocyte infiltration into the blood vessel wall. ${ }^{101}$ Studies on rats and mice have shown that the adventitial NAD(P)H oxidases, which are readily produced by fibroblasts, are the major sources of reactive oxygen species in cardiovascular diseases. ${ }^{102}$ Adventitial NAD $(\mathrm{P}) \mathrm{H}$ levels increase in response to mechanical forces acting on the blood vessel, such as the stretch of arteries by a balloon catheter. ${ }^{102}$ In addition, activated fibroblasts secrete proinflammatory cytokines and chemokines. Among those are IL-6, a cytokine involved in monocyte activation, as well as MCP-1, a monocyte chemoattractant. ${ }^{103}$ This suggests that activated fibroblasts are involved in both leukocyte recruitment and their activation in the adventitia. Using a combination of tissue culture and in vivo animal studies, Tieu et $\mathrm{al}^{103}$ displayed that AngII induces adventitial fibroblasts to express both IL-6 and MCP-1, ultimately resulting in monocyte recruitment, which, in turn, further enhanced fibroblast activation.
Adventitial inflammation has also been implicated in other cardiovascular diseases (namely, AAAs). In a histologic study of AAA human tissues, and interventional animal and cell culture experiments, Tsuruda et $\mathrm{al}^{104}$ found that the mast cells in the adventitia likely contribute to the development, progression, and/or rupture of AAAs. They observed increased mast cells in the aortic adventitia and outer media with advanced atherosclerosis and a further increase in AAA with a significant correlation between cell number and the maximal diameter of AAA. They suggested that the mast cells act by inducing apoptosis of SMCs and by activating matrix metalloproteinases, both of which disrupt the structural integrity of the vessel wall. In one such study using AngIIinduced AAA in mice, the investigators showed that the subpopulations of fibrogenic MSCs in the adventitia and media underwent proliferation and induced inflammation dependent on NF- $\kappa \beta /$ RelA proinflammatory transcription factor. ${ }^{105}$ These observations do not prove cause and effect but suggest that further studies designed to identify cause and effect are necessary. Moreover, the presence of ATLOs in the adventitia has also been linked to AAAs. In aged $\mathrm{ApoE}^{-1-}$ mice, Gräbner et $\mathrm{al}^{97}$ found that ATLO formation occurred preferentially in the abdominal aorta, where aortic aneurysms specially occur in both mice and humans. The investigators also observed elastic fiber erosion in medial regions adjacent to ATLOs, suggesting that they may contribute to AAA pathology. Recently, it was shown that ATLOs may serve as a potential source of miRNA biomarkers for AAAs. ${ }^{106}$

Graver et al ${ }^{107}$ observed significant infiltration of B cells in the aortic adventitia of patients with large-vessel giant cell arteritis. In most patients, these B cells were organized into ATLOs with germinal centers and plasma cell niches. This suggests a role of adventitial ATLOs in the pathogenesis of large-vessel giant cell arteritis.

\section{A Mechanistic Model to Design Future Research}

To conclude, although well away from the blood-wall interface where much pathology takes place, the adventitia has a profound influence on intimal and medial function in disease. On the basis of the histopathologic changes seen in these compartments, the activation of the response to injury is likely to occur at both sides of the wall, in the intimamedia and the adventitia. It is unclear which occurs first and may depend on the type of injury/disruption of the wall. It is not known if both compartments trigger activation or if pathology in one is a secondary effect of changes in the other and appears later in the progress of disease. What percentage does each side contribute to intimal thickening and to atherogenesis is also unknown. The interaction and the synergy of both sides with each other needs to be studied and understood. The recent knowledge acquired about the adventitia suggests a mechanistic model of adventitial 
dysfunction that identifies critical steps and that can be tested detailing interactions of the three layers (Figure 1). A comprehensive investigation of the constituents of the adventitia, both in normal physiology and in disease, is needed to understand how they interact and cross talk to promote and inhibit vascular disease. Two areas of cross talk that need careful study are between adventitia-PVAT and adventitia-media. This includes paracrine cell function, cell migration and differentiation, and diffusion of bioactive substances through the vascular tissue.

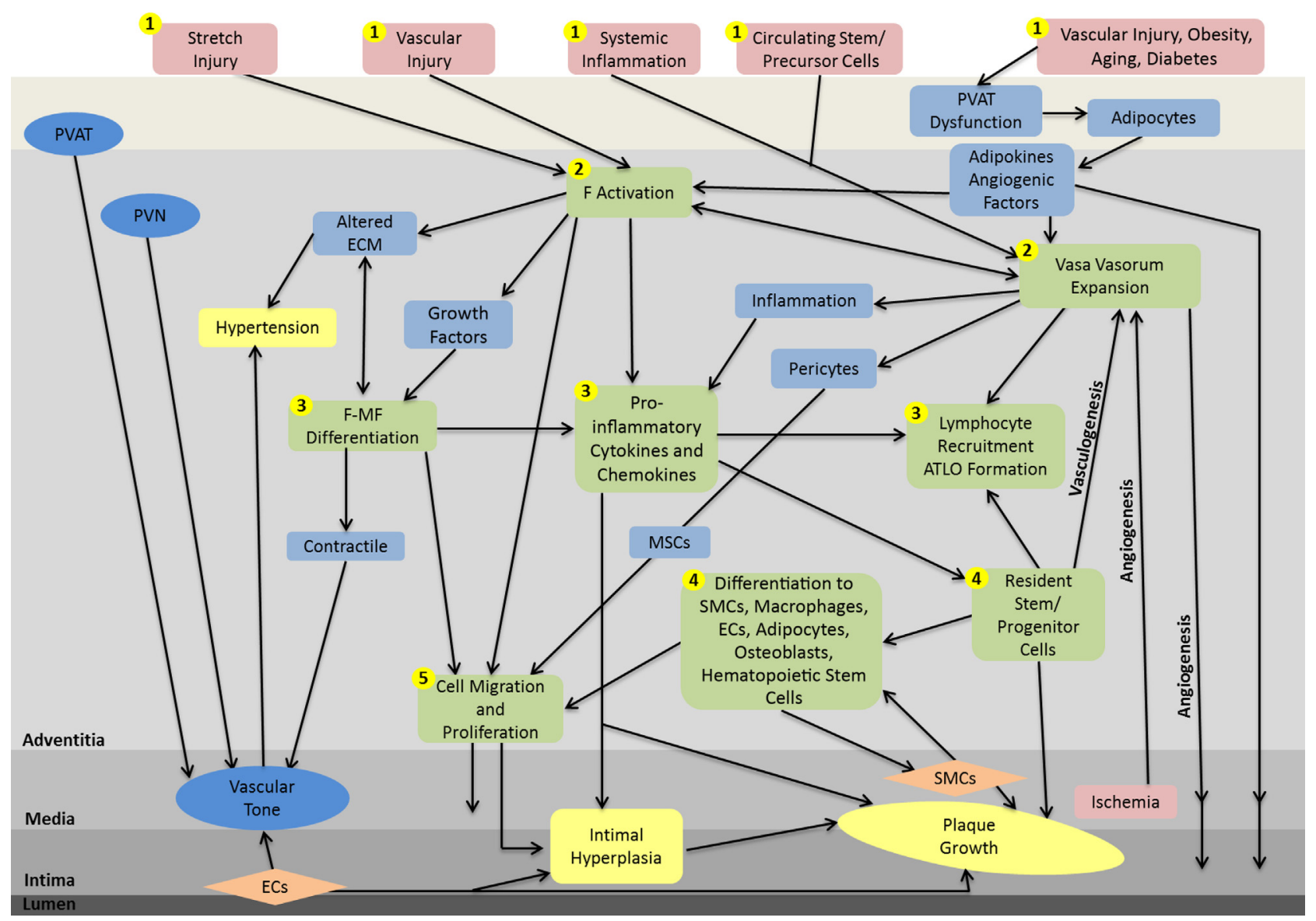

Figure 1 A model of vascular adventitial dysfunction in disease. There are several major steps in characterizing adventitial dysfunction in disease, especially intimal hyperplasia, atherosclerosis, and hypertension. Although several pathways can be consistent with the literature, one likely hypothesis of pathogenesis to test is that injury promotes fibroblast (F) activation and vasa vasorum (VV) expansion, leading to inflammation and $F$ differentiation in the adventitia. This then promotes stem cell differentiation as well as cell migration and proliferation in the intima-media. Thus, injury to the blood vessel (stretch of wall), systemic inflammation, circulating stem/progenitor cells, and/or perivascular adipose tissue (PVAT) dysfunction (1) leads to VV expansion and activation of adventitial Fs (2), which then promote the differentiation of Fs into myofibroblasts (MFs), inflammation, and the release of proinflammatory cytokines and chemokines, the recruitment of lymphocytes, and the formation of aortic tertiary lymphoid organs (ATLOs) in the adventitia (3). These pathologic changes promote the activation of adventitial stem/progenitor cells, which differentiate into smooth muscle cells (SMCs), macrophages, endothelial cells (ECs), adipocytes, osteoblasts, and hematopoietic stem cells (4). All these cells, along with Fs and MFs proliferate at enhanced rates and migrate into the intima-media, initiating and contributing to intimal hyperplasia and plaque growth (5). The activation and interactions among these adventitialderived cells, vessels, and matrix, however, are not well understood. Activated Fs release growth factors and angiogenic factors, promote remodeling of the extracellular matrix (ECM), and release proinflammatory cytokines and chemokines, which promote the infiltration of lymphocytes into the adventitia as well as the formation of ATLOs. MFs are contractile and produce proinflammatory cytokines. The VV is expanded by angiogenesis mediated by angiogenic and growth factors released from medial ischemic cells as well as by reactive oxygen species and adhesion molecules released by activated Fs. Some adventitial resident stem/progenitor cells also possess vasculogenic properties and may be a source of VV along with angiogenesis of existing VV. VV expansion allows for further infiltration of inflammatory cells and lymphocytes into the adventitia and the media and contributes to the activation of Fs. Vascular pericytes give rise to mesenchymal stem cells, which proliferate and migrate to the intima-media. SMCs, which migrate from the media to the adventitia, may also then differentiate into macrophages, ECs, adipocytes, osteoblasts, and hematopoietic stem cells. Vascular tone, important in atherogenesis, is regulated by molecules secreted by ECs, which have either vasoconstrictive or vasodilatory activity, by perivascular innervation of the adventitia via perivascular nerves (PVNs), and by paracrine influences from cells in the PVAT. Changes in tone and altered ECM promote hypertension. Molecules secreted by ECS and SMCs resident in the intima-media also promote plaque growth from the luminal side of the vessel wall. The relative importance between the adventitia and the intima-media in pathogenesis of vascular disease is yet to be determined. Triggers that promote important initial steps in disease are labeled in pink. The subsequent events and processes involved in regulating vascular dysfunction are labeled in green. Intermediate steps involved in the promotion of vascular dysfunction are labeled in light blue. Outcomes of vascular dysfunction are labeled in yellow. Cells of the inner layers of the blood vessel (intima and media) are labeled in orange. Factors contributing to changes in vascular tone are labeled in dark blue. (Vascular layers are not drawn to size.) 
Experiments must be designed to interrogate the structure and function of the adventitia in both in vitro and in vivo experimental models and in human tissue, especially focusing on the recent evidence that cells of the adventitia and media show plasticity. How this plasticity is regulated, especially in disease, needs to be well studied. All three layers, along with PVAT, should be studied simultaneously, not only the intima and media. This will help determine the validity of the outside-in hypothesis. The best way to study this correctly is through the use of animal models, and the two species best suited for this are the mouse and the pig. The former allows for genetic and cell lineage studies, whereas the latter provides a good physiological and pathophysiological model of the human arterial wall in which the adventitia is well separated from the intima-media, mimicking the adventitial complexities of the human aorta, coronary arteries, and large arteries. It is also likely that there will be some functional differences in regions along the aorta and its macrovascular branches, which need to be further studied.

\section{References}

1. Liu A, Gotlieb A: Blood vessels. Rubin's Pathology, ed 7. New York, NY: Wolters Kluwer, 2015. pp. 577-583

2. Nava E, Llorens $\mathrm{S}$ : The local regulation of vascular function: from an inside-outside to an outside-inside model. Front Physiol 2019, $10: 729$

3. Chaldakov GN, Beltowsky J, Ghenev PI, Fiore M, Panayotov P, Rančič G, Aloe L: Adipoparacrinology - vascular periadventitial adipose tissue (tunica adiposa) as an example. Cell Biol Int 2012, 36: 327-330

4. Lehoux S: Adventures in the adventitia. Hypertension 2016, 67: 836-838

5. Maiellaro K, Robert Taylor W, Taylor WR: The role of the adventitia in vascular inflammation. Cardiovasc Res 2007, 75:640-648

6. Stenmark KR, Yeager ME, El Kasmi KC, Nozik-Grayck E, Gerasimovskaya EV, Li M, Riddle SR, Frid MG: The adventitia: essential regulator of vascular wall structure and function. Annu Rev Physiol 2013, 75:23-47

7. Shi Y, Pieniek M, Fard A, O'Brien J, Mannion JD, Zalewski A: Adventitial remodeling after coronary arterial injury. Circulation 1996, 93:340-348

8. Silver FH, Hovarth I, Foran DJ: Mechanical implications of the domain structure of fiber-forming collagens: comparison of the molecular and fibrillar flexibilities of the $\alpha 1$-chains found in types I-III collagen. J Theor Biol 2002, 216:243-254

9. Lu X, Pandit A, Kassab GS: Biaxial incremental homeostatic elastic moduli of coronary artery: two-layer model. Am J Physiol Hear Circ Physiol 2004, 287:1663-1669

10. Gasser TC, Ogden RW, Holzapfel GA: Hyperelastic modelling of arterial layers with distributed collagen fibre orientations. J R Soc Interf 2005, 3:15-35

11. Chen H, Slipchenko MN, Liu Y, Zhao X, Cheng J-X, Lanir Y, Kassab GS: Biaxial deformation of collagen and elastin fibers in coronary adventitia. J Appl Physiol 2013, 115:1683-1693

12. Wagenseil JE, Mecham RP: Vascular extracellular matrix and arterial mechanics. Physiol Rev 2009, 89:957-989

13. Witter K, Tonar Z, Schöpper H: How many layers has the adventitia? structure of the arterial tunica externa revisited. Anat Histol Embryol 2017, 46:110-120
14. Gao YJ: Dual modulation of vascular function by perivascular adipose tissue and its potential correlation with adiposity/lipoatrophyrelated vascular dysfunction. Curr Pharm Des 2007, 13:2185-2192

15. Mulligan-Kehoe MJ, Simons M: Vasa vasorum in normal and diseased arteries. Circulation 2014, 129:2557-2566

16. Tonar Z, Tomášek P, Loskot P, Janáček J, Králíčková M, Witter K: Vasa vasorum in the tunica media and tunica adventitia of the porcine aorta. Ann Anat 2016, 205:22-36

17. Heistad DD, Marcus ML, Larsen GE, Armstrong ML: Role of vasa vasorum in nourishment of the aortic wall. Am J Physiol 1981, 240: 781-787

18. Moreno PR, Purushothaman K-R, Sirol M, Levy AP, Fuster V: Neovascularization in human atherosclerosis. Circulation 2006, 113: $2245-2252$

19. Boyle EC, Sedding DG, Haverich A: Targeting vasa vasorum dysfunction to prevent atherosclerosis. Vascul Pharmacol 2017, 96-98:5-10

20. Wolinsky H, Glagov S: Nature of species differences in the medial distribution of aortic vasa vasorum in mammals. Circ Res 1967, 20: 409-421

21. Geiringer E: Intimal vascularization and atherosclerosis. J Pathol Bacteriol 1951, 63:201-211

22. Loesch A, Dashwood MR: Vasa vasorum inside out/outside in communication: a potential role in the patency of saphenous vein coronary artery bypass grafts. J Cell Commun Signal 2018, 12: 631-643

23. Sano M, Unno N, Sasaki T, Baba S, Sugisawa R, Tanaka H, Inuzuka K, Yamamoto N, Sato K, Konno H: Topologic distributions of vasa vasorum and lymphatic vasa vasorum in the aortic adventitia: implications for the prevalence of aortic diseases. Atherosclerosis 2016, 247:127-134

24. Westcott EB, Segal SS: Perivascular innervation: a multiplicity of roles in vasomotor control and myoendothelial signaling. Microcirculation 2013, 20:217-238

25. Bevan JA: Some bases of differences in vascular response to sympathetic activity. Circ Res 1979, 45:161-171

26. Hirst GD, Edwards FR: Sympathetic neuroeffector transmission in arteries and arterioles. Physiol Rev 1989, 69:546-604

27. Luff SE: Ultrastructure of sympathetic axons and their structural relationship with vascular smooth muscle. Anat Embryol (Berl) 1996, 193:515-531

28. McLachlan EM: Transmission of signals through sympathetic ganglia: modulation, integration or simply distribution? Acta Physiol Scand 2003, 177:227-235

29. Furness JB, Marshall JM: Correlation of the directly observed responses of mesenteric vessles of the rat to nerve stimulation and noradrenaline with the distribution of adrenergic nerves. J Physiol 1974, 239:75-88

30. Rhodin JA: The ultrastructure of mammalian arterioles and precapillary sphincters. J Ultrastruct Res 1967, 18:181-223

31. Passman JN, Rong Dong X, Wu S-P, Maguire CT, Hogan KA, Bautch VL, Majesky MW: A sonic hedgehog signaling domain in the arterial adventitia supports resident Scal smooth muscle progenitor cells. PNAS USA 2008, 105:9349-9354

32. Chen Y, Wong MM, Campagnolo P, Simpson R, Winkler B, Margariti A, Hu Y, Xu Q: Adventitial stem cells in vein grafts display multilineage potential that contributes to neointimal formation. Arterioscler Thromb Vasc Biol 2013, 33:1844-1851

33. Zengin E, Chalajour F, Gheling UM, Ito WD, Treede H, Lauke H, Weil J, Reichenspurner H, Kilic N, Ergun S: Vascular wall resident progenitor cells: a source for postnatal vasculogenesis. Development 2006, 133:1543-1551

34. Torsney E, Mandal K, Halliday A, Jahangiri M, Xu Q: Characterisation of progenitor cells in human atherosclerotic vessels. Atherosclerosis 2007, 191:259-264

35. Hu Y, Zhang Z, Torsney E, Afzal AR, Davison F, Metzler B, Xu Q: Abundant progenitor cells in the adventitia contribute to 
atherosclerosis of vein grafts in ApoE-deficient mice. J Clin Invest 2004, 113:1258-1265

36. Majesky MW, Horita H, Ostriker A, Lu S, Regan JN, Bagchi A, Dong XR, Poczobutt J, Nemenoff RA: Weiser-Evans MCM: Differentiated smooth muscle cells generate a subpopulation of resident vascular progenitor cells in the adventitia regulated by Klf4. Circ Res 2017, 120:296-311

37. Michelis KC, Nomura-Kitabayashi A, Lecce L, Franzén O, Koplev S, Xu Y, Santini MP, D'Escamard V, Lee JTL, Fuster V, Hajjar R, Reddy RC, Chikwe J, Stelzer P, Filsoufi F, Stewart A, Anyanwu A, Björkegren JLM, Kovacic JC: CD90 identifies adventitial mesenchymal progenitor cells in adult human medium- and large-sized arteries. Stem Cell Reports 2018, 11:242-257

38. Corselli M, Chen C-W, Sun B, Yap S, Rubin JP, Péault B: The tunica adventitia of human arteries and veins as a source of mesenchymal stem cells. Stem Cells Dev 2012, 21:1299-1308

39. Crisan M, Yap S, Casteilla L, Chen C-W, Corselli M, Park TS, Andriolo G, Sun B, Zheng B, Zhang L, Norotte C, Teng P-N, Traas J, Schugar R, Deasy BM, Badylak S, Bühring H-J, Giacobino J-P, Lazzari L, Huard J, Péault B: A perivascular origin for mesenchymal stem cells in multiple human organs. Stem Cell 2008, 3:301-313

40. Tigges U, Komatsu M, Stallcup WB: Adventitial pericyte progenitor/mesenchymal stem cells participate in the restenotic response to arterial injury. J Vasc Res 2013, 50:134-144

41. Psaltis PJ, Harbuzariu A, Delacroix S, Witt TA, Holroyd EW, Spoon DB, Hoffman SJ, Pan S, Kleppe LS, Mueske CS, Gulati R, Sandhu GS, Simari RD: Identification of a monocyte-predisposed hierarchy of hematopoietic progenitor cells in the adventitia of postnatal murine aorta. Circulation 2012, 125:592-603

42. Psaltis PJ, Puranik AS, Spoon DB, Chue CD, Hoffman SJ, Witt TA, Delacroix S, Kleppe LS, Mueske CS, Pan S, Gulati R, Simari RD: Characterization of a resident population of adventitial macrophage progenitor cells in postnatal vasculature. Circ Res 2014, 115: 364-375

43. Toledo-Flores D, Williamson A, Schwarz N, Fernando S, Dimasi C, Witt TA, Nguyen TM, Puranik AS, Chue CD, Delacroix S, Spoon DB, Bonder CS, Bursill CA, Di Bartolo BA, Nicholls SJ, Simari RD, Psaltis PJ: Vasculogenic properties of adventitial Sca$1+\mathrm{CD} 45+$ progenitor cells in mice: a potential source of vasa vasorum in atherosclerosis. Sci Rep 2019, 9:7286

44. Mekala SR, Wörsdörfer P, Bauer J, Stoll O, Wagner N, Reeh L, Loew K, Eckner G, Kwok CK, Wischmeyer E, Dickinson ME, Schulze H, Stegner D, Benndorf RA, Edenhofer F, Pfeiffer V, Kuerten S, Frantz S, Ergün S: Generation of cardiomyocytes from vascular adventitia-resident stem cells. Circ Res 2018, 123:686-699

45. Allaire E, Schneider F, Saucy F, Dai J, Cochennec F, Michineau S, Zidi M, Becquemin J-P, Kirsch M, Gervais M: New insight in aetiopathogenesis of aortic diseases. Eur J Vasc Endovasc Surg 2009, $37: 531-537$

46. Gavrila D, Li WG, McCormick ML, Thomas M, Daugherty A, Cassis LA, Miller FJ, Oberley LW, Dellsperger KC, Weintraub NL, Weintraub NL: Vitamin E inhibits abdominal aortic aneurysm formation in angiotensin II-infused apolipoprotein E-deficient mice. Arterioscler Thromb Vasc Biol 2005, 25:1671-1677

47. Tanaka H, Zaima N, Sasaki T, Sano M, Yamamoto N, Saito T, Inuzuka K, Hayasaka T, Goto-Inoue N, Sugiura Y, Sato K, Kugo H, Moriyama T, Konno H, Setou M, Unno N: Hypoperfusion of the adventitial vasa vasorum develops an abdominal aortic aneurysm. PLoS One 2015, 10:1-23

48. Liu X, Wu H, Byrne M, Krane S, Jaenisch R: Type III collagen is crucial for collagen I fibrillogenesis and for normal cardiovascular development. PNAS USA 1997, 94:1852-1856

49. Heegaard A-M, Corsi A, Danielsen CC, Nielsen KL, Jorgensen HL, Riminucci M, Young MF, Bianco P: Biglycan deficiency causes spontaneous aortic dissection and rupture in mice. Circulation 2007, 115:2731-2738
50. Miyata H, Imai H, Koseki H, Shimizu K, Abekura Y, Oka M, Kawamata T, Matsuda T, Nozaki K, Narumiya S, Aoki T: Vasa vasorum formation is associated with rupture of intracranial aneurysms. J Neurosurg 2019, 16:1-11

51. Barger AC, Beeuwkes R, Lainey LL, Silverman KJ: Hypothesis: vasa vasorum and neovascularization of human coronary arteries. N Engl J Med 1984, 310:175-177

52. Arcidiacono MV, Rubinat E, Borras M, Betriu A, Trujillano J, Vidal T, Mauricio D, Fernández E: Left carotid adventitial vasa vasorum signal correlates directly with age and with left carotid intima-media thickness in individuals without atheromatous risk factors. Cardiovasc Ultrasound 2015, 13:1-6

53. Moulton KS, Vakili K, Zurakowski D, Soliman M, Butterfield C, Sylvin E, Lo K-M, Gillies S, Javaherian K, Folkman J: Inhibition of plaque neovascularization reduces macrophage accumulation and progression of advanced atherosclerosis. Circulation 2003, 100: $4736-4741$

54. Hytönen JP, Taavitsainen J, Laitinen JTT, Partanen A, Alitalo K, Leppänen O, Ylä-Herttuala S: Local adventitial anti-angiogenic gene therapy reduces growth of vasa-vasorum and in-stent restenosis in WHHL rabbits. J Mol Cell Cardiol 2018, 121:145-154

55. de Vries MR, Parma L, Peters HAB, Schepers A, Hamming JF, Jukema JW, Goumans THMJ, Guo L, Finn AV, Virmani R, Ozaki CK, Quax PHA, Hab P, Mjth G: Blockade of vascular endothelial growth factor receptor 2 inhibits intraplaque haemorrhage by normalization of plaque neovessels. J Intern Med 2019, 285:59-74

56. Kwon HM, Sangiorgi G, Ritman EL, McKenna C, Holmes DR, Schwartz RS, Lerman A: Enhanced coronary vasa vasorum neovascularization in experimental hypercholesterolemia. J Clin Invest 1998, 101:1551-1556

57. Drozdz K, Janczak D, Dziegiel P, Podhorska M, Piotrowska A, Patrzalek D, Andrzejak R, Szuba A: Adventitial lymphatics and atherosclerosis. Lymphology 2012, 45:26-33

58. Barker SG, Talbert A, Cottam S, Baskerville PA, Martin JF: Arterial intimal hyperplasia after occlusion of the adventitial vasa vasorum in the pig. Arterioscler Thromb 1993, 13:70-77

59. Hamaoka-Okamoto A, Suzuki C, Yahata T, Ikeda K, Nagi-Miura N, Ohno N, Arai Y, Tanaka H, Takamatsu T, Hamaoka K: The involvement of the vasa vasorum in the development of vasculitis in animal model of Kawasaki disease. Pediatr Rheumatol Online J 2014, $12: 12$

60. Xu F, Ji J, Li L, Chen R, Hu W: Activation of adventitial fibroblasts contributes to the early development of atherosclerosis: a novel hypothesis that complements the "response-to-injury hypothesis" and the "inflammation hypothesis." Med Hypotheses 2007, 69:908-912

61. Hinz B, Phan SH, Thannickal VJ, Prunotto M, Desmoulière A, Varga J, De Wever O, Mareel M, Gabbiani G: Review recent developments in myofibroblast biology paradigms for connective tissue remodeling. Am J Pathol 2012, 180:1340-1355

62. Guimarães-Camboa N, Evans SM: Are perivascular adipocyte progenitors mural cells or adventitial fibroblasts? Cell Stem Cell 2017, 20:587-589

63. Vishvanath L, Long JZ, Spiegelman BM, Gupta RK: Do adipocytes emerge from mural progenitors? Cell Stem Cell 2017, 20:585-586

64. Coen M, Gabbiani G, Bochaton-Piallat M-L: Myofibroblast-mediated adventitial remodeling an underestimated player in arterial pathology. Arter Thromb Vasc Biol 2011, 31:2391-2396

65. Li M, Riddle SR, Frid MG, El Kasmi KC, McKinsey TA, Sokol RJ, Strassheim D, Meyrick B, Yeager ME, Flockton AR, McKeon BA, Lemon DD, Horn TR, Anwar A, Barajas C, Stenmark KR: Emergence of fibroblasts with a proinflammatory epigenetically altered phenotype in severe hypoxic pulmonary hypertension. J Immunol 2011, 187:2711-2722

66. Hinz B: Myofibroblasts. Exp Eye Res 2016, 142:56-70

67. An SJ, Liu P, Shao TM, Wang ZJ, Lu HG, Jiao Z, Li X, Fu JQ: Characterization and functions of vascular adventitial fibroblast subpopulations. Cell Physiol Biochem 2015, 35:1137-1150 
68. Das M, Dempsey EC, Reeves JT, Stenmark KR: Selective expansion of fibroblast subpopulations from pulmonary artery adventitia in response to hypoxia. Am J Physiol Cell Mol Physiol 2002, 282: 976-986

69. Han W-Q, Wu L-Y, Zhou H-Y, Zhang J, Che Z-Q, Wu Y-J, Liu J-J, Zhu D-L, Gao P-J: Changes in the composition of the thoracic aortic wall in spontaneuously hypertensive rats treated with losartan or spironolactone. Clin Exp Pharmacol Physiol 2009, 36:583-588

70. Sartore S, Chiavegato A, Faggin E, Franch R, Puato M, Ausoni S, Pauletto P: Contribution of adventitial fibroblasts to neointima formation and vascular remodeling from innocent bystander to active participant. Circ Res 2001, 89:1111-1121

71. Li M, Riddle S, Zhang H, D'Alessandro A, Flockton A, Serkova NJ, Hansen KC, Moldvan R, McKeon BA, Frid M, Kumar S, Li H, Liu H, Caánovas A, Medrano JF, Thomas MG, Iloska D, PlecitáHlavatá L, Ježek P, Pullamsetti S, Fini MA, El Kasmi KC, Zhang Q, Stenmark KR: Metabolic reprogramming regulates the proliferative and inflammatory phenotype of adventitial fibroblasts in pulmonary hypertension through the transcriptional corepressor C-terminal binding protein-1. Circulation 2016, 134:1105-1121

72. Dutzmann J, Koch A, Weisheit S, Sonnenschein K, Korte L, Haertlé M, Thum T, Bauersachs J, Sedding DG, Daniel J-M: Sonic hedgehog-dependent activation of adventitial fibroblasts promotes neointima formation. Cardiovasc Res 2017, 113:1653-1663

73. Barman SA, Fulton D: Adventitial fibroblast Nox4 expression and ROS signaling in pulmonary arterial hypertension. Adv Exp Med Biol 2017, 967:1-11

74. Barman SA, Chen F, Su Y, Dimitropoulou C, Wang Y, Catravas JD, Han W, Orfi L, Szantai-Kis C, Keri G, Szabadkai I, Barabutis N, Rafikova O, Rafikov R, Black SM, Jonigk D, Giannis A, Asmis R, Stepp DW, Ramesh G, Fulton DJR: NADPH oxidase 4 is expressed in pulmonary artery adventitia and contributes to hypertensive vascular remodeling. Arterioscler Thromb Vasc Biol 2014, 34: $1704-1715$

75. Chan EC, Peshavariya HM, Liu G-S, Jiang F, Lim S-Y, Dusting GJ: Nox4 modulates collagen production stimulated by transforming growth factor $\beta 1$ in vivo and in vitro. Biochem Biophys Res Commun 2013, 430:918-925

76. Li N, Cheng W, Huang T, Yuan J, Wang X, Song M: Vascular adventitia calcification and its underlying mechanism. PLoS One 2015, 10:1-12

77. Fleenor BS, Bowles DK: Negligible contribution of coronary adventitial fibroblasts to neointimal formation following balloon angioplasty in swine. Am J Physiol Heart Circ Physiol 2009, 296: H1532-H1539

78. Scott NA, Cipolla GD, Ross CE, Dunn B, Martin FH, Simonet L, Wilcox JN: Identification of a potential role for the adventitia in vascular lesion formation after balloon overstretch injury of porcine coronary arteries. Circulation 1996, 93:2178-2187

79. Zhang L, Chen Y, Li G, Chen M, Huang W, Liu Y, Li Y: TGF$\beta 1 / F G F-2$ signaling mediates the 15-HETE-induced differentiation of adventitial fibroblasts into myofibroblasts. Lipids Health Dis 2016, $15: 1-8$

80. Chang Z, Paoletti P, Barrett SD, Chim YH, Caamaño-Gutiérrez E, Hansen ML, Beck HC, Rasmussen LM, Akhtar R: Nanomechanics and ultrastructure of the internal mammary artery adventitia in patients with low and high pulse wave velocity. Acta Biomater 2018, 73:437-448

81. Pan X, Ruan C, Liu X, Kong L, Ma Y, Wu Q, Li H, Sun Y, Chen A, Zhao Q, Wu F, Wang X, Wang J, Zhu D, Gao P: Perivascular adipose tissue derived stromal cells contribute to vascular remodeling during aging. Aging Cell 2019, 18:1-13

82. Zhu X, Zhang H, Chen H, Deng X, Tu Y, Jackson AO, Qing J, Wang A, Patel V, Yin K: Perivascular adipose tissue dysfunction aggravates adventitial remodeling in obese mini pigs via NLRP3 inflammasome/IL-1 signaling pathway. Acta Pharmacol Sin 2019, 40: $46-54$
83. Chang L, Milton H, Eitzman DT, Chen E: Paradoxical roles of perivascular adipose tissue in atherosclerosis and hypertension. Circ J 2013, 77:11-18

84. Okamoto E, Couse T, De Leon H, Vinten-Johansen J, Goodman RB, Scott NA, Wilcox JN: Perivascular inflammation after balloon angioplasty of porcine coronary arteries. Circulation 2001, 104: $2228-2235$

85. Ling L, Chen D, Tong Y, Zang Y-H, Ren X-S, Zhou H, Qi X-H, Chen Q, Li Y-H, Kang Y-M, Zhu G-Q: Fibronectin type III domain containing 5 attenuates NLRP3 inflammasome activation and phenotypic transformation of adventitial fibroblasts in spontaneously hypertensive rats. J Hypertens 2018, 36:1104-1114

86. Huang G, Cong Z, Wang X, Yuan Y, Xu R, Lu Z, Wang X, Qi J: Targeting HSP90 attenuates angiotensin II-induced adventitial remodelling via suppression of mitochondrial fission. Cardiovasc Res 2019, [Epub ahead of print] doi:10.1093/cvr/cvz194

87. Galkina E, Kadl A, Sanders J, Varughese D, Sarembock IJ, Ley K: Lymphocyte recruitment into the aortic wall before and during development of atherosclerosis is partially L-selectin dependent. J Exp Med 2006, 203:1273-1282

88. Jongstra-Bilen J, Haidari M, Zhu S-N, Chen M, Guha D, Cybulsky MI: Low-grade chronic inflammation in regions of the normal mouse arterial intima predisposed to atherosclerosis. J Exp Med 2006, 203:2073-2083

89. Moos MPW, John N, Gräbner R, Noßmann S, Günther B, Vollandt R, Funk CD, Kaiser B, Habenicht AJR: The lamina adventitia is the major site of immune cell accumulation in standard chow-fed apolipoprotein E-deficient mice. Arter Thromb Vasc Biol 2005, 25:2386-2391

90. Houtkamp MA, de Boer OJ, van der Loos CM, van der Wal AC, Becker AE: Adventitial infiltrates associated with advanced atherosclerotic plaques: structural organization suggests generation of local humoral immune responses. J Pathol 2001, 193:263-269

91. Campbell KA, Lipinski MJ, Doran AC, Skaflen MD, Fuster V, McNamara CA: Lymphocytes and the adventitial immune response in atherosclerosis. Circ Res 2012, 110:889-900

92. Sakamoto S, Tsuruda T, Hatakeyama K, Imamura T, Asada Y, Kitamura K: Impact of age-dependent adventitia inflammation on structural alteration of abdominal aorta in hyperlipidemic mice. PLoS One 2014, 9:e105739

93. Zhang X, Liu F, Bai P, Dong N, Chu C: Identification of key genes and pathways contributing to artery tertiary lymphoid organ development in advanced mouse atherosclerosis. Mol Med Rep 2019, 19: 3071-3086

94. Yin C, Mohanta SK, Srikakulapu P, Weber C, Habenicht AJR: Artery tertiary lymphoid organs: powerhouses of atherosclerosis immunity. Front Immunol 2016, 7:387

95. Weih F, Gräbner R, Hu D, Beer M, Habenicht AJR, Ley K, Naldini A: Control of dichotomic innate and adaptive immune responses by artery tertiary lymphoid organs in atherosclerosis. Front Physiol 2012, 3:226

96. Akhavanpoor M, Gleissner CA, Akhavanpoor H, Lasitschka F, Doesch AO, Katus HA, Erbel C: Adventitial tertiary lymphoid organ classification in human atherosclerosis. Cardiovasc Pathol 2018, 32: $8-14$

97. Gräbner R, Lötzer K, Döpping S, Hildner M, Radke D, Beer M, Spanbroek R, Lippert B, Reardon CA, Getz GS, Fu Y-X, Hehlgans T, Mebius RE, van der Wall M, Kruspe D, Englert C, Lovas A, Hu D, Randolph GJ, Weih F, Habenicht AJR: Lymphotoxin beta receptor signaling promotes tertiary lymphoid organogenesis in the aorta adventitia of aged ApoE-/- mice. J Exp Med 2009, 206:233-248

98. Rademakers T, Douma K, Hackeng TM, Post MJ, Sluimer JC, Daemen MJAP, Biessen EAL, Heeneman S, van Zandvoort MAMJ: Plaque-associated vasa vasorum in aged apolipoprotein E-deficient mice exhibit proatherogenic functional features in vivo. Arterioscler Thromb Vasc Biol 2013, 33:249-256 
99. Langheinrich AC, Sedding DG, Kampschulte M, Moritz R, Wilhelm J, Haberbosch WG, Ritman EL, Bohle RM: 3-Deazaadenosine inhibits vasa vasorum neovascularization in aortas of ApoE-//LDL-/- double knockout mice. Atherosclerosis 2009, 202:103-110

100. Li X-D, Hong M-N, Chen J, Lu Y-Y, Ye M-Q, Yu M, Zhu D-L, Gao P-J: Adventitial fibroblast-derived VEGF promotes vasa vasorum-associated neointima formation and macrophage recruitment. Cardiovasc Res 2019, [Epub ahead of print] doi:10.1093/cvr/ cvz159

101. Csányi G, Robert Taylor W, Pagano PJ: NOX and inflammation in the vascular adventitia. Free Radic Biol Med 2009, 47: $1254-1266$

102. Haurani MJ, Pagano PJ: Adventitial fibroblast reactive oxygen species as autocrine and paracrine mediators of remodeling: bellwether for vascular disease? Cardiovasc Res 2007, 75:679-689

103. Tieu BC, Ju X, Lee C, Sun H, Lejeune W, Recinos A, Brasier AR, Tilton RG, Tilton RG: Aortic adventitial fibroblasts participate in angiotensin-induced vascular wall inflammation and remodeling. $\mathrm{J}$ Vasc Res 2011, 48:261-272
104. Tsuruda T, Kato J, Hatakeyama K, Kojima K, Yano M, Yano Y, Nakamura K, Nakamura-Uchiyama F, Matsushima Y, Imamura T, Onitsuka T, Asada Y, Nawa Y, Eto T, Kitamura K: Adventitial mast cells contribute to pathogenesis in the progression of abdominal aortic aneurysm. Circ Res 2008, 102:1368-1377

105. Ijaz T, Sun H, Pinchuk IV, Milewicz DM, Tilton RG, Brasier AR: Deletion of NF-KB/RelA in angiotensin II-sensitive mesenchymal cells blocks aortic vascular inflammation and abdominal aortic aneurysm formation. Arterioscler Thromb Vasc Biol 2017, 37: $1881-1890$

106. Spear R, Boytard L, Blervaque R, Chwastyniak M, Hot D, Vanhoutte J, Staels B, Lemoine Y, Lamblin N, Pruvot F-R, Haulon S, Amouyel P, Pinet F: Adventitial tertiary lymphoid organs as potential source of microRNA biomarkers for abdominal aortic aneurysm. Int J Mol Sci 2015, 16:11276-11293

107. Graver JC, Boots AMH, Haacke EA, Diepstra A, Brouwer E, Sandovici M: Massive B-cell infiltration and organization into artery tertiary lymphoid organs in the aorta of large vessel giant cell arteritis. Front Immunol 2019, 10:83 